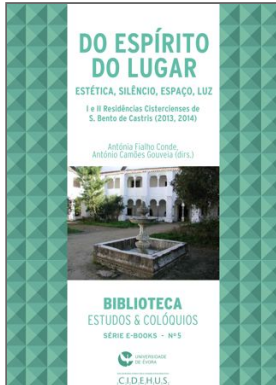

Antónia Fialho Conde and António Camões Gouveia (dir.)

Do Espírito do Lugar - Música, Estética, Silêncio, Espaço, Luz

I e II Residências Cistercienses de São Bento de Cástris (2013, 2014)

\title{
Metodologia para avaliação exploratória do comportamento acústico da Igreja do Mosteiro de S. Bento de Cástris, Évora
}

João C. G. Lanzinha, Miguel C. S. Nepomuceno, Ana Maria Tavares Martins, Carla Reis and Albino A.S. Alves

Publisher: Publicações do Cidehus

Place of publication: Évora

Year of publication: 2016

Published on OpenEdition Books: 13

septembre 2016

Serie: Biblioteca - Estudos \& Colóquios

\section{Q books}

http://books.openedition.org

\section{Electronic reference}

LANZINHA, João C. G. ; et al. Metodologia para avaliação exploratória do comportamento acústico da Igreja do Mosteiro de S. Bento de Cástris, Évora In: Do Espírito do Lugar - Música, Estética, Silêncio, Espaço, Luz: I e II Residências Cistercienses de São Bento de Cástris (2013, 2014) [online]. Évora: Publicações do Cidehus, 2016 (generated 27 October 2016). Available on the Internet: <http://books.openedition.org/ cidehus/2124>. ISBN: 9782821875029. DOI: 10.4000/books.cidehus.2124. 
Metodologia para avaliação exploratória do comportamento acústico da Igreja do Mosteiro de S. Bento de Cástris, Évora

\section{João C. G. Lanzinha*, Miguel C. S. Nepomuceno**, Ana M. T. Martins ${ }^{* * *}$, Carla P.L. Reis ${ }^{* * * *}$, Albino A.S. Alves ${ }^{* * * * *}$}

Resumo

A igreja do Mosteiro de S. Bento de Cástris em Évora (séc. XIV-XIX) apresenta uma tipologia de configuração de espaços pouco comum e que parece privilegiar diferentes posicionamentos para o funcionamento de grupos corais de apoio às atividades litúrgicas e de expressão musical.

Tratando-se de possíveis opções de carácter empírico, pois são relativamente recentes os conhecimentos científicos no domínio da física das construções e em especial da acústica de edifícios, importa explorar, com medições no local, as condições reais de comportamento acústico e em especial conhecer os tempos de reverberação e comparar os resultados obtidos com as recomendações atuais para este tipo de espaços.

Nesta comunicação caracteriza-se a igreja do ponto de vista da conceção e seus principais aspetos construtivos, explica-se o significado e interesse da medição dos tempos de reverberação e apresenta-se a metodologia estabelecida para explorar as condições acústicas da igreja objeto de estudo

Palavras-chave: arquitetura cisterciense, acústica, reverberação, S. Bento de Cástris

\section{Abstract}

The church of the Monastery of S. Bento de Cástris, in Évora $\left(14^{\text {th }}-19^{\text {th }}\right.$ centuries $)$ has an uncommon spatial typology that seems to privilege the possibility of offering different positions to the choirs that supported both the liturgical and the musical activities.

Considering that these were possibly empirical options, because the scientificknowledge

\footnotetext{
* (DECA-UBI, C-MADE, LABSED) - é engenheiro civil e a sua investigação recai sobre a inspecção, diagnóstico e intervenção no edificado assim como a reabilitação de edifícios, tendo sido responsável, no âmbito do Projecto ORFEUS, pelo estudo acústico da Igreja de S. Bento de Cástris

** (DECA-UBI, C-MADE) - é engenheiro civil e a sua investigação recai sobre a Física das Construções, Tecnologia da Construção e Materiais, tendo sido responsável, no âmbito do Projecto ORFEUS, pelo estudo acústico da Igreja de S. Bento de Cástris.

*** (DECA-UBI, Lab2PT, CIDEHUS)

**** (DECA-UBI)

***** (DECA-UBI) - Albino Alves tem formação base em engenharia civil e apoia tecnicamente a investigação, no âmbito da patologia e conservação dos edifícios, tendo sido responsável, no contexto do Projecto ORFEUS, pelo estudo acústico da Igreja de S. Bento de Cástris.
} 
on buildings physics and, particularly, on building acoustics are relatively recent, it is important to explore, with on-site measurements, the real acoustic behavior conditions, specifically the reverberation times, and compare the results obtained with the current recommendations for this type of spaces.

In this paper we characterize the church in terms of design and of its main construction features, explaining the meaning and interest of measuring its reverberation times and presenting the methodology defined for exploring the acoustic conditions of the church under study.

Keywords: cistercian architecture, acoustic, reverberation, S. Bento de Cástris

\section{Introdução}

Nos espaços destinados à prática religiosa é fundamental a audição de sons agradáveis, com um nível adequado e que proporcionem um ambiente propício para o silêncio, a reflexão, a exploração da identidade interior e a audição da palavra e de música sacra com a qualidade adequada.

A conceção acústica de um espaço que se prevê ser destinado a atividades religiosas pode ser realizada e otimizada com recurso à modelação e simulação através de aplicações informáticas ou de medições em modelos reduzidos, definindo a melhor organização e configuração dos espaços e as volumetrias mais adequadas e escolhendo os revestimentos superficiais para proporcionar as condições desejadas. Já o estudo e tratamento acústico de espaços existentes, muitas vezes em imóveis de interesse histórico ou patrimonial, apresentam alguma complexidade, pois nem sempre é possível alterar as situações existentes, devido à distribuição, configuração e volumetria desses espaços e diferentes tipos de revestimentos e ornamentação das superfícies interiores.

A transmissão caótica das ondas sonoras num recinto fechado e especialmente reverberante ocasiona sempre problemas de inteligibilidade da palavra, que tornam os espaços desagradáveis para os utilizadores. Estes espaços podem ser convenientemente estudados e os problemas solucionados com recurso a soluções de correção acústica. Para o efeito é necessário explorar, com medições no local, as condições reais de comportamento acústico e em especial conhecer os tempos de reverberação e comparar os resultados obtidos com as recomendações atuais para este tipo de espaços.

A igreja do Mosteiro de S. Bento de Cástris em Évora (séc. XIV-XIX) apresenta uma tipologia de configuração de espaços pouco comum, contemplando dois diferentes posicionamentos para o coro de suporte para as atividades litúrgicas da comunidade 
religiosa: o coro alto no prolongamento da nave da igreja, num nível superior ao da assembleia, e o coro baixo na zona lateral da capela-mor. A dúvida que se coloca e que se pretende explorar é se esta configuração teria como objetivo privilegiar diferentes posicionamentos de grupos corais e outras formas de expressão musical.

A acústica de espaços religiosos mais antigos foi desenvolvida, provavelmente, com base em formulações empíricas pois são relativamente recentes os conhecimentos científicos no domínio da física das construções e em especial da acústica de edifícios. Propõe-se nesta comunicação apresentar a metodologia definida no sentido de explorar as condições acústicas da igreja do Mosteiro de S. Bento de Cástris em Évora com recurso a medições no local.

\section{Características da igreja objeto de estudo}

O Mosteiro de S. Bento de Cástris está classificado como Monumento Nacional desde 1922 e situa-se no Alentejo, implantando-se no Alto de São Bento, a cerca de dois quilómetros da cidade de Évora (Figs. 1 e 2).

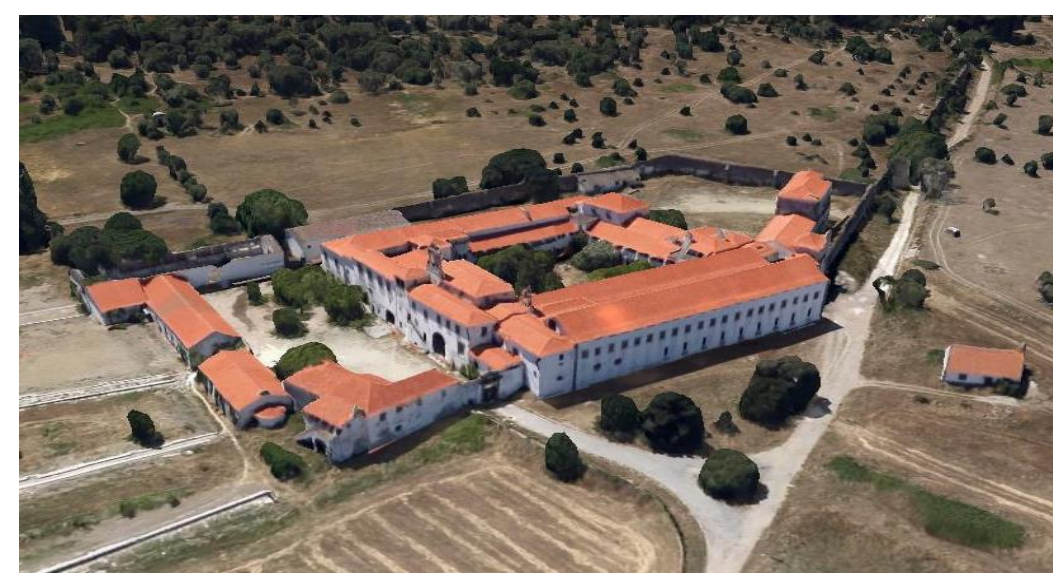

Fig. 1 - Imagem do Mosteiro de S. Bento de Cástris 


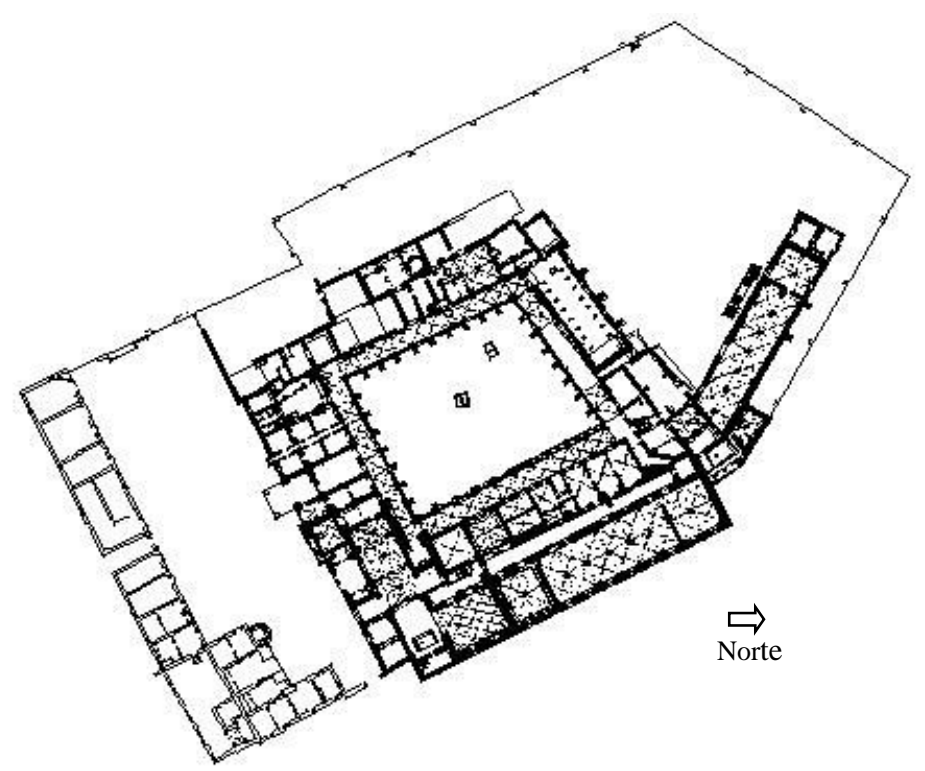

Fig. 2 - Planta do Mosteiro de S. Bento de Cástris (sem escala)

O edifício, enquanto mosteiro da Ordem de Cister, remonta ao século XIII se o considerarmos no pleno das funções e com construção da igreja, sala do capítulo, ala das Monjas e todas as dependências de apoio à subsistência da comunidade tais como refeitório e cozinha [1]. O edifício monástico que hoje subsiste apresenta, no seu conjunto, características arquitetónicas que se enquadram num período entre o fim do século XV e o início do século XVI, podendo ainda encontrar-se vestígios do gótico final assim como influências mudéjares conciliadas com as exigências cistercienses.

A igreja do Mosteiro apresenta características Quinhentistas sendo de destacar a abóbada Manuelina de alvenaria com nervuras, terminando os arcos torais e formeiros em meias colunas [1]. Salienta-se o descentramento do transepto em relação à nave da igreja o que indicia vestígios de uma anterior construção. A igreja possui uma planta biaxial, de cruz latina, apresentando uma nave única e transepto (Figs. 3 e 4). A nave possui três tramos (Fig. 5) medindo os dois primeiros (relativos ao transepto e tramo intermédio) $5,70 \mathrm{~m} \mathrm{x}$ $6,80 \mathrm{~m}$ e o terceiro $5,70 \mathrm{~m} \times 3,50 \mathrm{~m}$ [1]. O último tramo e parte do seguinte é ocupado pelo coro alto (Fig. 6) ainda com vestígios góticos.

$\mathrm{O}$ acesso à igreja é feito lateralmente à nave, como ocorria nos mosteiros femininos, abrindo-se parte desta à comunidade secular de maneira a não 
perturbar ou quebrar a clausura ficando a sacristia a sul da ábside permitindo igualmente o acesso do Capelão quando celebrasse a Eucaristia. O braço sul do transepto permite o acesso à sacristia (Fig. 7) e ao púlpito (Fig. 8). O braço oposto do transepto possui um confessionário e um acesso, atualmente emparedado, que daria acesso à ala das monjas.

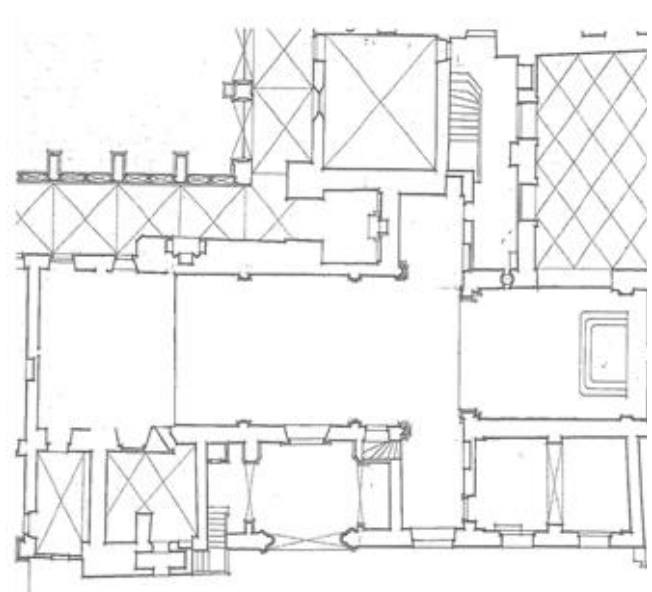

Fig. 3 - Planta da igreja (sem escala)

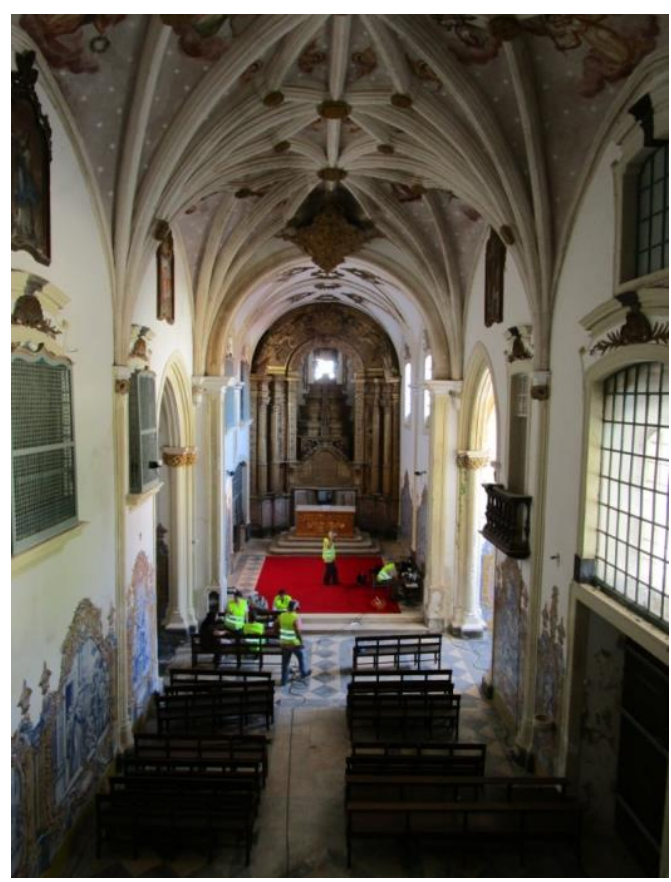

Fig. 5 - Nave da igreja vista a partir do coro alto

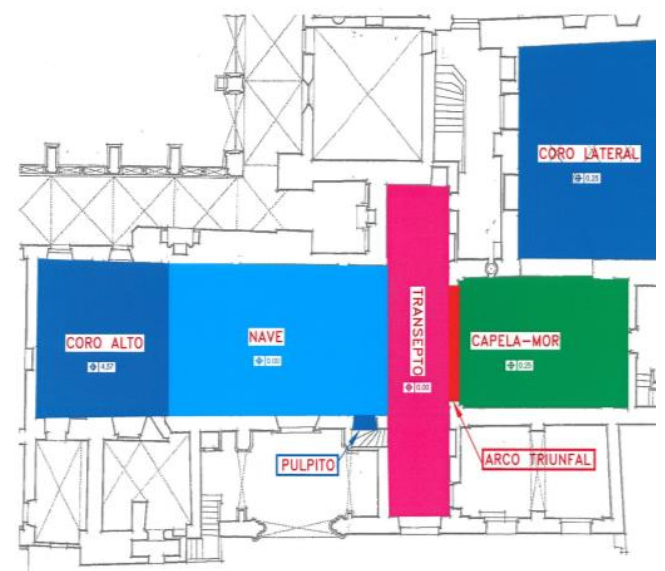

Fig. 4 - Identificação dos espaços

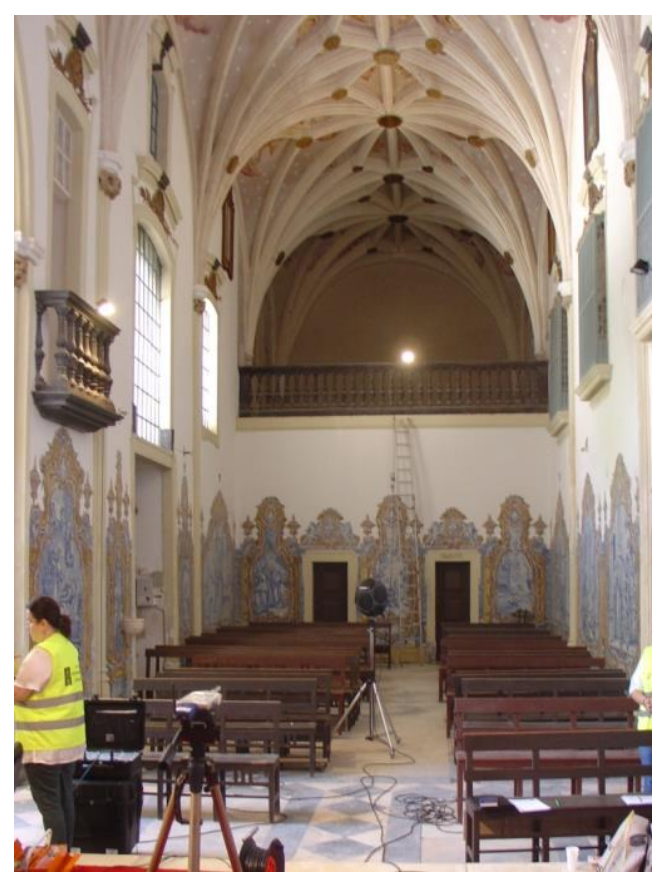

Fig. 6 - Coro alto visto da nave 


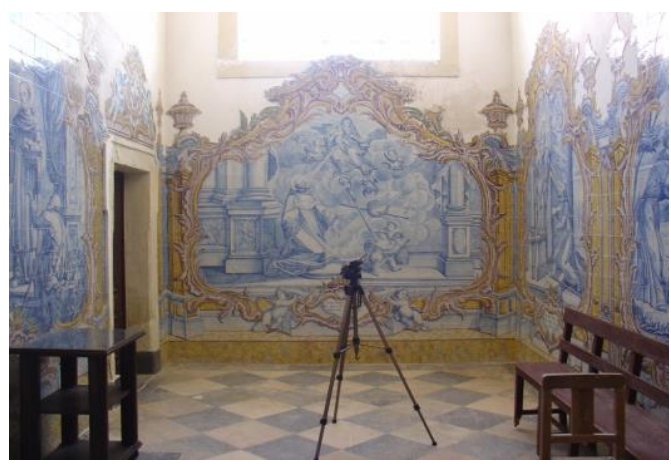

Fig. 7 - Acesso à sacristia através do transepto

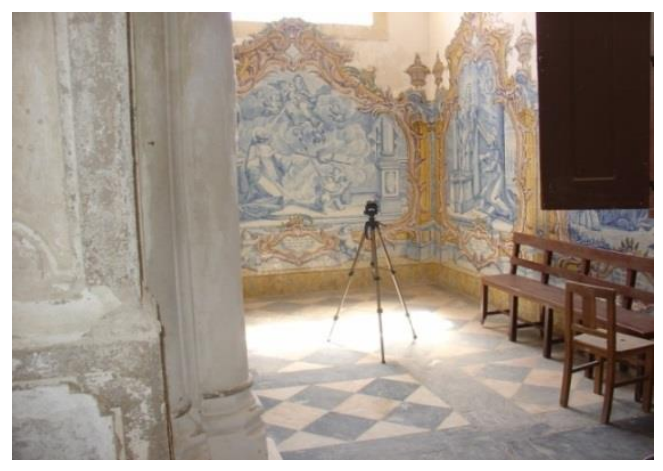

Fig. 8 - Acesso ao púlpito através do transepto

É no século XVI que surge o coro lateral que é constituído por uma abóbada abatida, e invulgarmente baixa, sobre a qual é colocado um revestimento de caixotões losangulares (Fig. 9). O acesso ao coro lateral faz-se junto ao altar (Fig. $10)$.

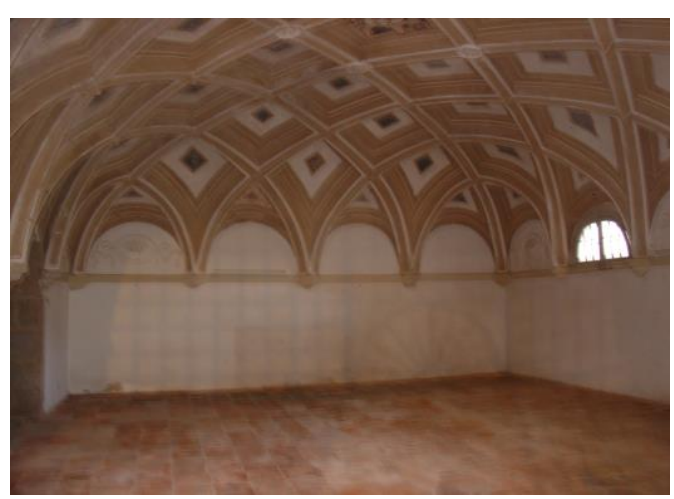

Fig. 9 - Abóbada do coro lateral

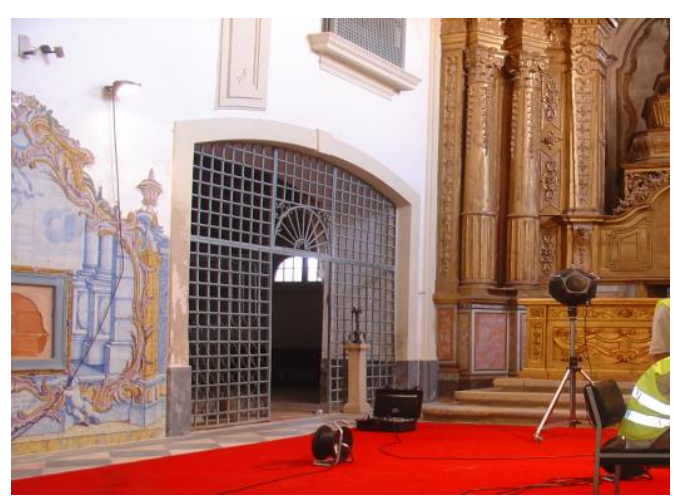

Fig. 10 - Acesso ao coro lateral

Ao longo do tempo o edifício foi sendo adaptado às novas realidades e solicitações. Durante o séc. XVIII surgem novas intervenções na igreja sobretudo de cariz decorativo, de estilo rococó, patentes na talha, no estuque e nos azulejos (Figs. 5 a 8). Após a extinção das Ordens Religiosas, em 1834, novos usos surgem nestes edifícios. Em 1890 morre a última religiosa sendo o Mosteiro extinto e ficando o edifício apto para outros usos em consonância com o decreto de 1834. A partir de 1941 o edifício passa a pertencer à DGEMN (Direção Geral de Edifícios e Monumentos Nacionais) mas já em 1937 se iniciam obras de conservação no mesmo [2]. Destaca-se a utilização do Mosteiro de S. Bento de Cástris como Casa Pia de Évora - Secção Baptista Rolo até 2004 e após o seu abandono surge, em 
2006, a tentativa de acolher o Museu Nacional da Música por parte do Ministério da Cultura [2].

No que se refere aos revestimentos das diferentes superfícies interiores que constituem o recinto e que contribuem para as caraterísticas do comportamento acústico interior da igreja deve-se ter em conta a existência de diferentes materiais.

As paredes da nave são constituídas por alvenaria rebocada e ornamentada por silhares de azulejos existindo no lado norte da nave da igreja aberturas emparedadas que apresentam uma grelha em madeira e alguma decoração em talha dourada com cariz vegetalista (Fig. 11). Os vãos de acesso à igreja são fechados por portas de madeira destacando-se a existência da grade de ferro no coro lateral que faz a separação deste da ábside. As aberturas que permitem a iluminação na igreja são igualmente realizadas com recurso a caixilharia de madeira e vidro simples contabilizando-se dois janelões na parede sul da igreja, um no braço sul do transepto (Fig. 12) e dois na capela-mor aos quais acresce uma abertura, a nascente, no topo da ábside.

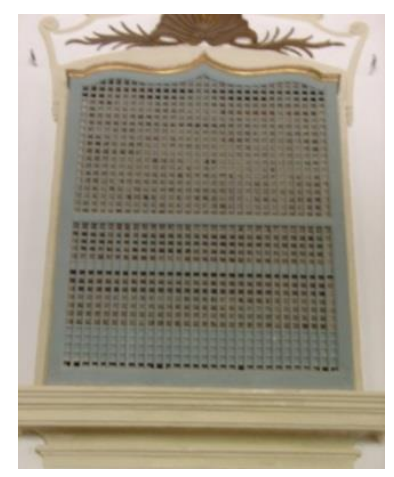

Fig. 11 - Aberturas emparedadas

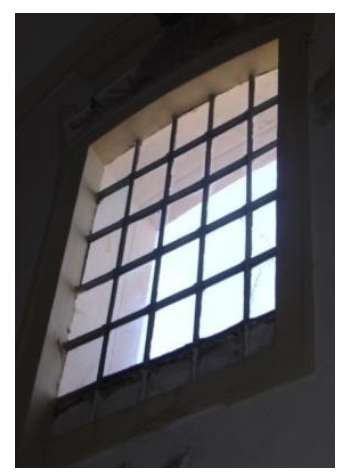

Fig. 12 - Envidraçado do transepto

O teto da igreja é abobadado com nervuras e constituído por alvenaria revestida por estuque (Figs. 5 e 6). Um arco triunfal de volta perfeita demarca a nave da capela-mor (Fig. 5). Esta demarcação é também obtida através de elevação em dois degraus da ábside em relação ao nível do pavimento da nave. A ábside possui um retábulo e trono do século XVIII, em talha dourada, assim como um altar no mesmo material (elevado três degraus em relação ao pavimento da capela-mor). 
O pavimento da nave é constituído por mármore sendo o pavimento da capelamor constituído por uma combinação de mármore e granito que, nos finais do século XX, é recoberta por alcatifa (Fig. 10). No que diz respeito aos pavimentos dos coros lateral e alto ambos são constituídos por mármore.

Atualmente existem bancos de madeira corridos na nave. No que respeita a património móvel, tanto o coro alto como o coro lateral possuíam cadeirais em madeira. No arquivo do SIPA/IHRU ainda se podem observar fotografias do cadeiral do coro alto, em madeira, com retábulos policromos [3]. No coro lateral, devido ao invulgar achatamento, o encosto dos cadeirais atingia a cornija. Atualmente já não existe este cadeiral sendo apenas visíveis as paredes rebocadas e um silhar de azulejo com padrão aleatório (possivelmente o local onde se encontrava a cadeira da Abadessa). A nascente, sobre a cornija, encontram-se no coro lateral duas aberturas circulares com caixilharia em madeira e vidro simples. As religiosas cumpriam os preceitos de clausura estando separadas através de grades e cortinas tanto no coro lateral como no coro alto (note-se que a grade do coro alto não subsistiu, tendo sido substituída por uma balaustrada em madeira). Esta separação impedia o contacto visual entre a comunidade religiosa e a secular sem, no entanto, perturbar a audição.

Regista-se o facto de partes substanciais das paredes da nave e do transepto terem sido revestidas no século XVIII com azulejo cerâmico de cor azul e branca com moldura polícroma retratando cenas da vida de S. Bernardo (Fig. 13). Este material de revestimento é muito pouco absorvente das ondas sonoras e, quando comparado com o comportamento dos revestimentos a estuque tradicional, terá contribuído para o aumento da reverberação no recinto e para a alteração das características acústicas originais. $\mathrm{O}$ mesmo terá acontecido com a alteração das caraterísticas dimensionais do coro alto com a consequente diminuição do seu volume. 


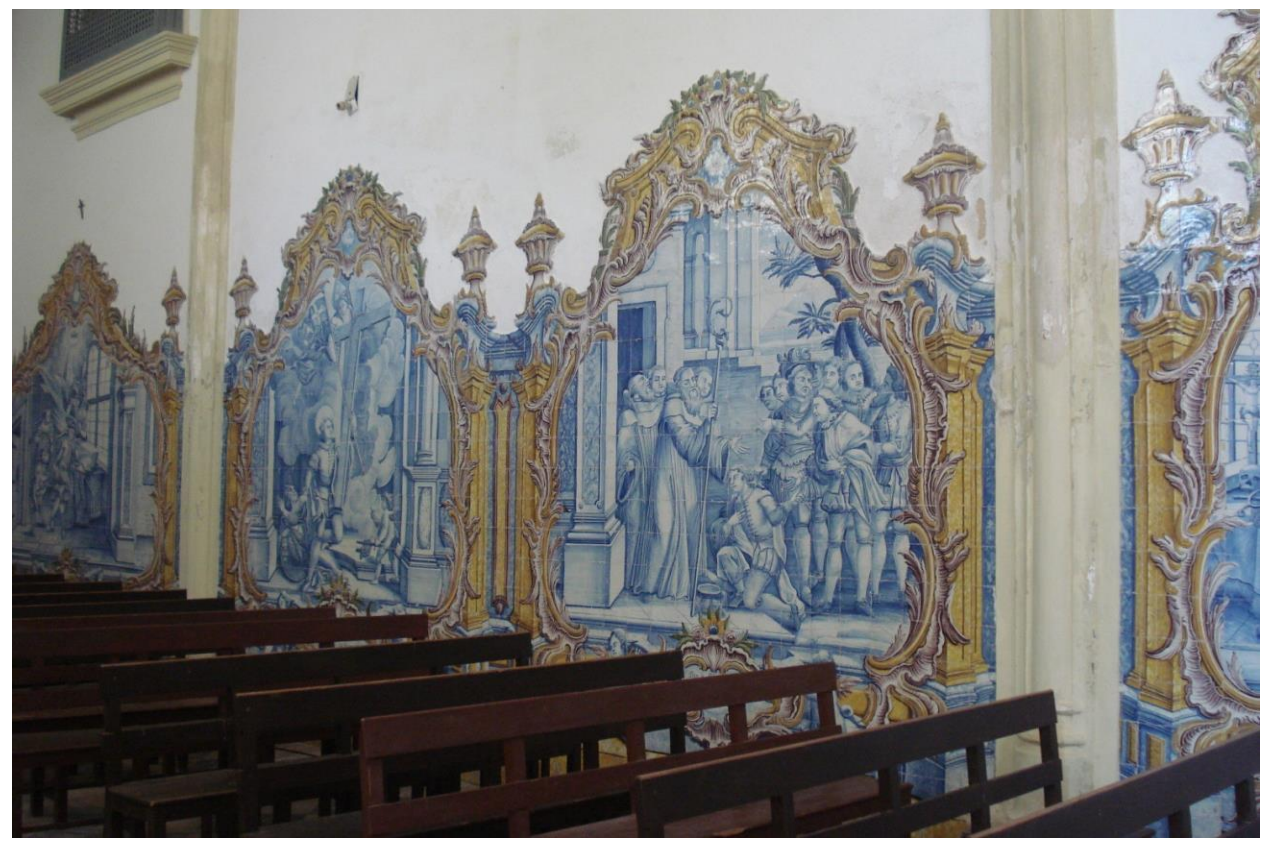

Fig. 13 - Revestimento com azulejo com cenas da vida de S. Bernardo

\section{Determinação dos tempos de reverberação}

\subsection{A reverberação e a inteligibilidade do som}

A reverberação pode ser explicada como a persistência do som num recinto fechado devido às sucessivas reflexões das ondas sonoras nas superfícies delimitadoras do espaço considerado. Quando se trata de efetuar medições acústicas é considerada a persistência do campo sonoro estabelecido pela fonte sonora para além do instante em que esta deixa de emitir. O tempo de reverberação, $T r$, é considerado o principal parâmetro objetivo para traduzir a perceção humana subjetiva da reverberação e é definido como o intervalo de tempo necessário para que a energia volúmica do campo sonoro de um recinto fechado se reduza a um milionésimo do seu valor inicial [4], ou, noutros termos, o tempo correspondente ao decaimento de $60 \mathrm{~dB}$ do nível sonoro.

O tempo de reverberação pode ser avaliado localmente com recurso a medições acústicas ou estimado com recurso a fórmulas empíricas, cujo exemplo mais conhecido é a fórmula proposta por Sabine. De acordo com a fórmula de Sabine, o tempo de reverberação depende da frequência do som, do volume interior do recinto e da absorção sonora dos materiais das superfícies delimitadoras do recinto e de eventuais objetos existentes no seu interior. 
A medição do tempo de reverberação é feita com base na norma EN ISO 3382-2 [5]. A metodologia preconizada nesta norma consiste no registo direto do decaimento do nível de pressão sonora após a excitação do compartimento com ruído de banda larga ou por um ruído de bandas previamente definidas. A curva de decaimento consiste, pois, na representação gráfica do decaimento do nível de pressão sonora num compartimento, em função do tempo, após a emissão da fonte sonora ter sido interrompida (Fig. 14).

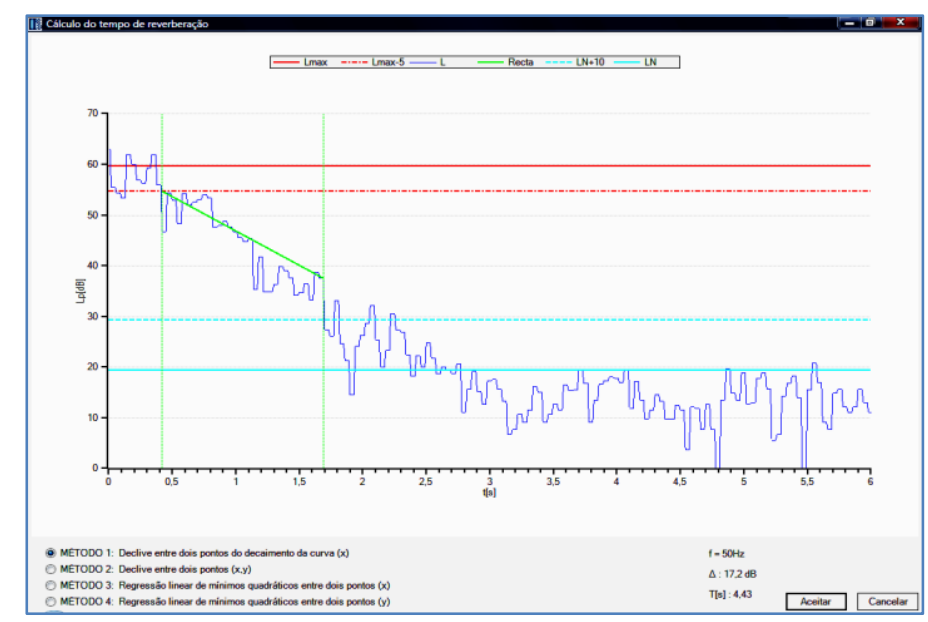

Fig. 14 - Exemplo de curva de decaimento medida experimentalmente

Para diferentes atividades desenvolvidas em recintos fechados, que envolvam o uso da palavra ou atividade musical, com volumes diferenciados e para determinada frequência do som, são recomendados valores diferentes para o tempo de reverberação, $T r$. Uma das referências é um ábaco (Fig. 15) proposto por Rigden (1985) na publicação "Physics and the Sound of Music" [6] no qual se propõem tempos de reverberação em função do volume do recinto e do tipo de atividade prevista.

A regulamentação portuguesa [4] estabelece que os recintos cuja principal valência corresponda a atividades assentes na oratória, nomeadamente auditórios, salas de conferência, salas polivalentes e salas de cinema, devem cumprir requisitos relativamente ao tempo de reverberação. Em tais edifícios, a regulamentação estabelece que o tempo de reverberação médio, $T r$, nas bandas de oitava centradas nas frequências de 500, 1000 e $2000 \mathrm{~Hz}$, deve satisfazer as 
condições que a seguir se apresentam, quando mobilados normalmente e sem ocupação, onde $V$ representa o volume interior do recinto em metros cúbicos.

i) $\operatorname{Tr} \leq 0,12 V^{1 / 3}$, se $V<250 \mathrm{~m}^{3}$

ii) $\operatorname{Tr} \leq 0,32+0,17 \log V$, se $250 \leq V<9000 \mathrm{~m}^{3}$

iii) $\operatorname{Tr} \leq 0,05 V^{1 / 3}$, se $V \geq 9000 \mathrm{~m}^{3}$;

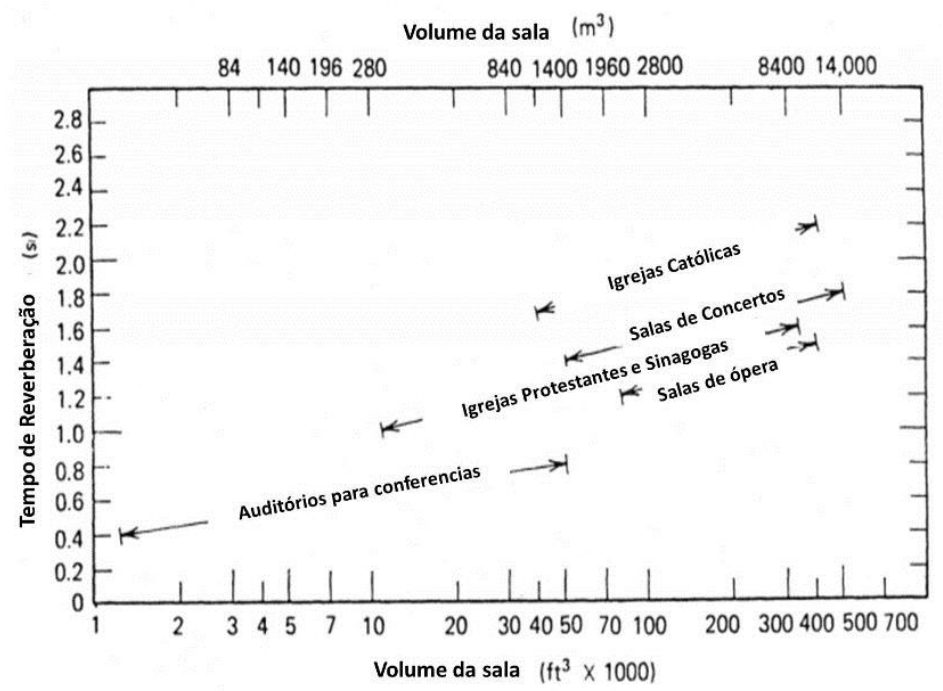

Fig. 15 - Tempo de reverberação ideal [6]

Prevê ainda a referida regulamentação que o projeto de condicionamento acústico destes espaços deve incluir um estudo específico destinado a assegurar uma característica de reverberação adequada no restante espectro de frequências e uma boa inteligibilidade da palavra nos diversos locais do recinto [4].

\subsection{Etapas e equipamento utilizado no desenvolvimento do estudo}

A aplicação da norma EN ISO 3382-2 [5] ao caso de estudo contemplou a medição do tempo de reverberação. Esta medição foi executada com o apoio de um conjunto de equipamentos para medição acústica disponibilizados pelo Laboratório de Saúde na Edificação (LABSED) do UBIMedical, que inclui uma fonte sonora omnidirecional, recetor e software de apoio com as seguintes caraterísticas principais:

a) Fonte sonora composta por altifalante omnidirecional Cesva BP012 e gerador de ruído/amplificador Cesva AP601 (Figs. 16 e 17) - Diagrama de diretividade 
completamente omnidirecional, $123 \mathrm{~dB}$ de Potência Acústica, gerador de ruído branco, rosa e rosa filtrado, bandas de $1 / 3$ de oitava $50-5000 \mathrm{~Hz}$, controlo via cabo, controle remoto ou transmissão via aérea Bluetooth (integrado no AP601) e sistema de refrigeração por ar forçado apagando o ventilador automaticamente (para a medição de ruído de fundo).

b) Sonómetro integrador e analisador de espectro em tempo real Cesva SC 310 (Fig. 18), da Classe 1, analisador espectral por bandas de terços de oitavas e oitavas. Mede todos os parâmetros simultaneamente com as ponderações frequenciais A, C e Z. Escala única e módulos de ampliação: medição do tempo de reverberação e análise espectral expandida e medição de vibrações e módulo dosímetro para a avaliação do ruído laboral.

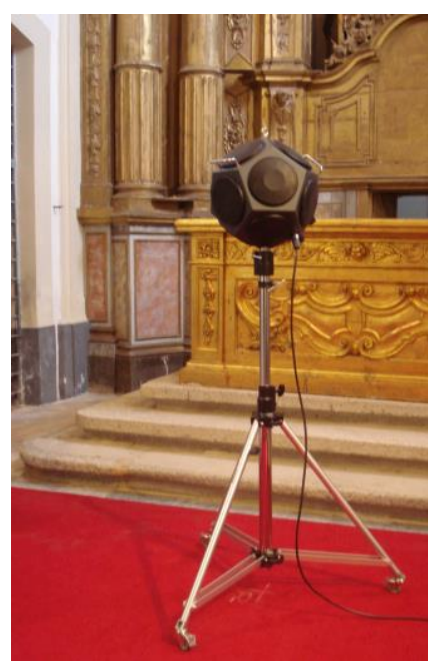

Fig. 16 - Fonte sonora omnidirecional

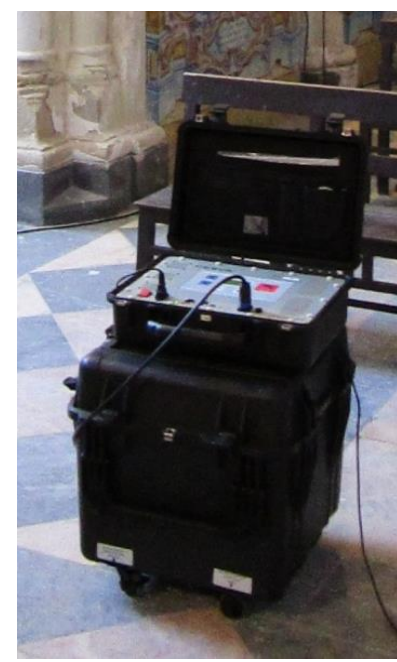

Fig. 17 - Amplificador

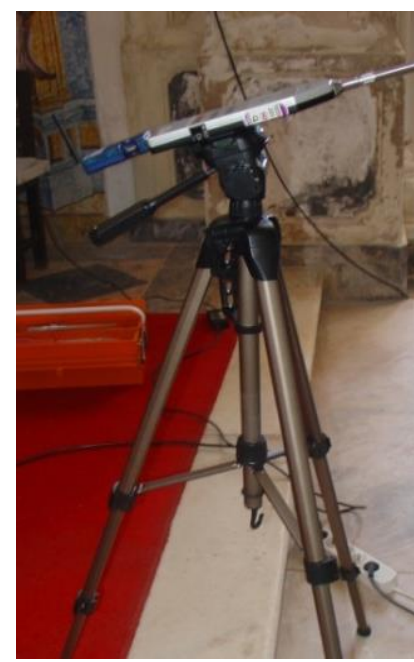

Fig. 18 - Sonómetro

c) Software de apoio à medição CMA - Cesva Measuring Assistant e software para o cálculo e emissão de relatórios CIS - Cesva Insulation Studio. O software de apoio à medição tem várias funcionalidades. Antes da medição permite importar plantas, selecionar pontos de medição e comprovar as condições da envolvente (distâncias entre pontos de medição, dispositivos e limites dos recintos). Durante as medições (Figs. 19 e 20) faz a gestão automática dos dispositivos (fontes de ruído e recetor) e guia o operador na realização das medições (posicionamento do equipamento e ligação da fonte de ruído, por 
exemplo). Permite verificar em tempo real os resultados das diferentes medições (ruído de fundo, espetros medidos, etc.) e repetir a aquisição de dados em caso de necessidade. Após as medições interatua com o software CIS para obter o relatório final no local de medição.

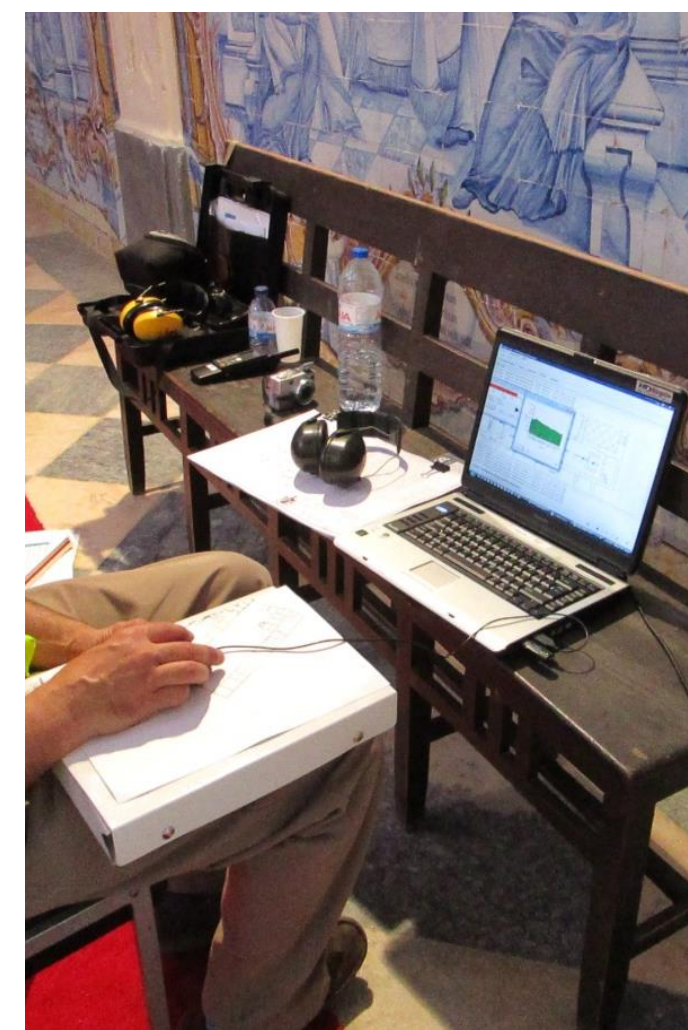

Fig. 19 - Equipamento informático

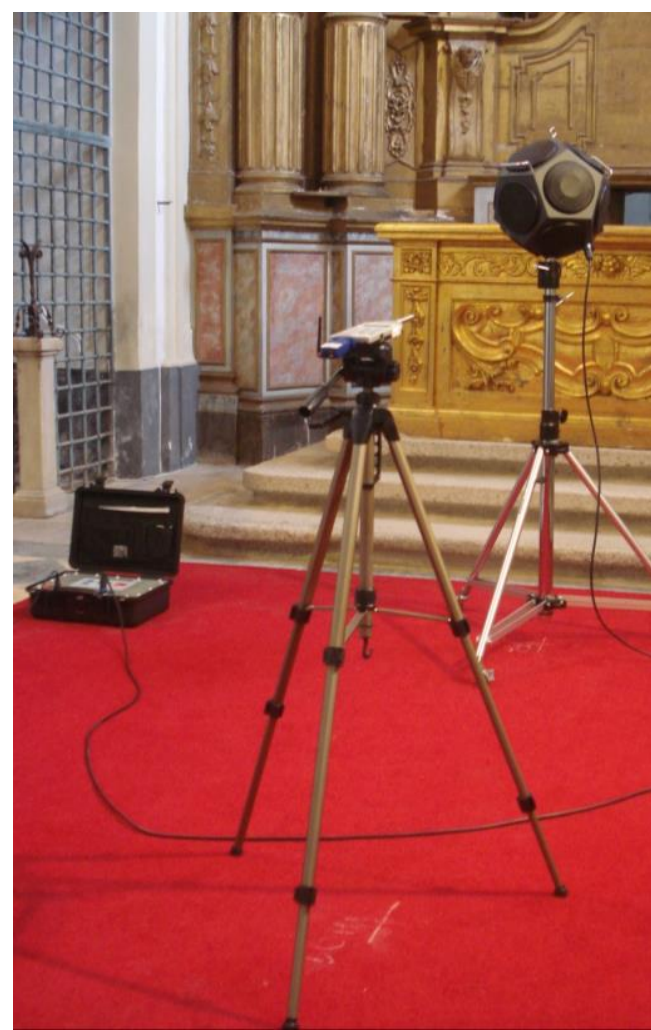

Fig. 20 - Imagem de conjunto

\subsection{Metodologia adotada no caso de estudo}

Para recintos com área superior a $50 \mathrm{~m}^{2}$, a norma EN ISO 3382-2 [5] prevê para o processo de determinação do tempo de reverberação duas posições para a fonte sonora e seis posições para o recetor, com a medição de dois decaimentos em cada posição, num total de doze decaimentos. Sendo objetivo do presente estudo caracterizar o tempo de reverberação na igreja do Mosteiro de S. Bento de Cástris, com um volume aproximado de $2319 \mathrm{~m}^{3}$, e explorar em maior detalhe as possíveis razões para a existência de dois coros, entendeu-se adequado densificar o número de leituras. 
A Figura 21 ilustra o esquema de posicionamento adotado para a fonte sonora e recetor, nela identificando-se 7 posições para a fonte sonora (F01 a F07) e 14 posições para o recetor (R01 a R14).

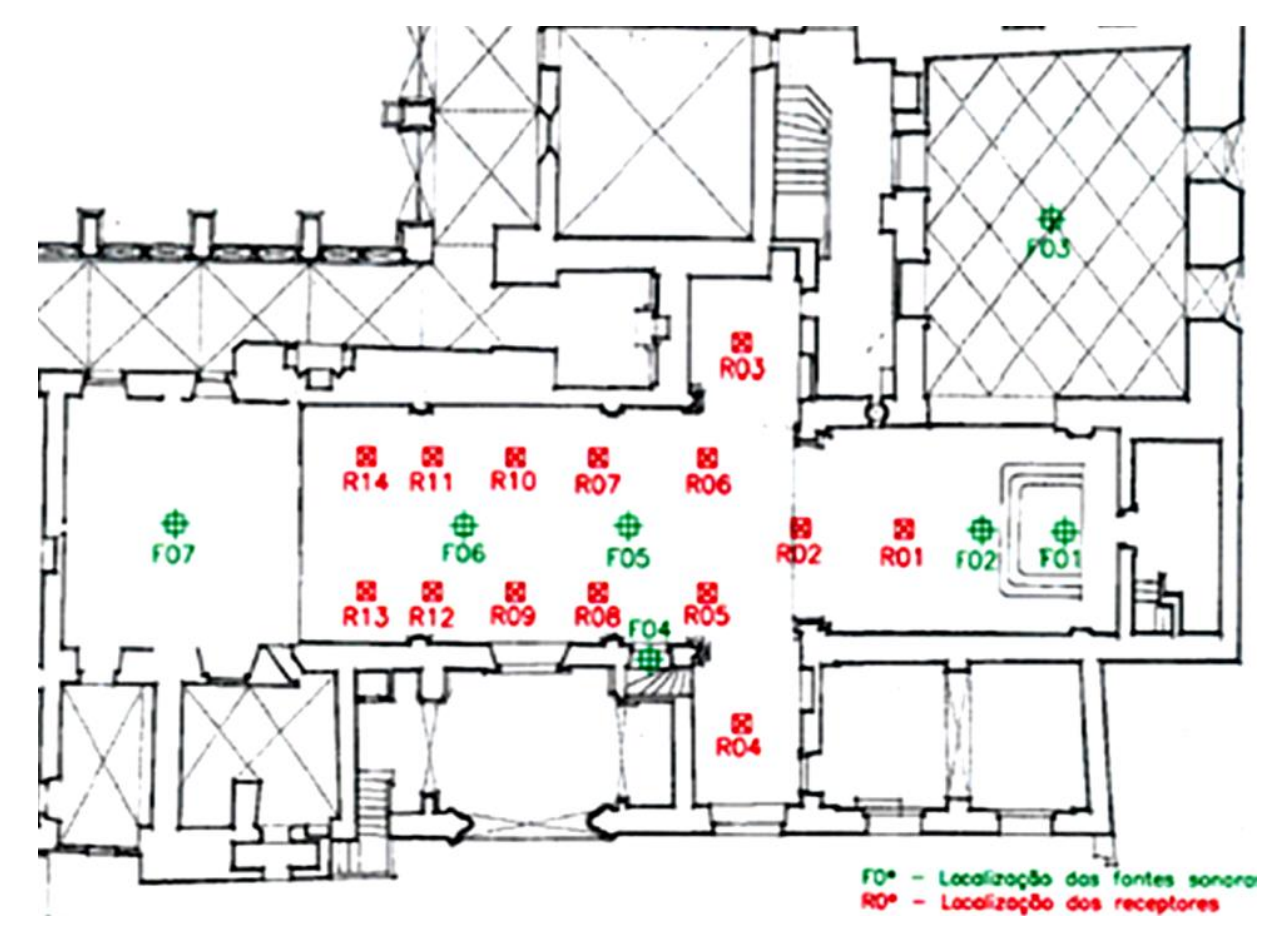

Fig. 21 - Esquema do posicionamento de fontes sonoras e recetores

As posições da fonte sonora foram determinadas em função das principais caraterísticas de utilização do espaço: F01 (altar), F02 (em frente ao altar, após Concílio Vaticano II), F03 (coro lateral), F04 (púlpito), F05 (nave), F06 (nave) e F07 (coro alto). Como se ilustrou na Figura 8, as posições dos recetores foram distribuídas uniformemente pelos diferentes espaços utilizáveis da igreja procurando medir de forma circunstanciada as caraterísticas do tempo de reverberação no recinto. A Figura 22 ilustra uma imagem da medição com a fonte sonora na posição F05 e o recetor na posição R02, enquanto a Figura 23 ilustra a fonte sonora na posição F04 e o recetor na posição R01.

No posicionamento dos equipamentos de medição houve ainda a preocupação de evitar que as superfícies da envolvente interferissem nas leituras. Assim, adotouse um afastamento mínimo de $1 \mathrm{~m}$ relativamente a paredes e pavimentos, uma distância mínima de $2 \mathrm{~m}$ entre locais de medição, uma altura da fonte sonora de 
1,5 $\mathrm{m}$ acima do pavimento e uma altura do sonómetro de 1,2 $\mathrm{m}$ acima do pavimento.

Os trabalhos de medição do tempo de reverberação na igreja do Mosteiro de S. Bento de Cástris foram realizados de forma contínua no dia 30 de julho de 2014, registando-se no ambiente interior do recinto uma temperatura de $29{ }^{\circ} \mathrm{C}$ e humidade relativa de 48\%. O número total de medições foi de 196 (resultantes da combinação de 7 posições da fonte sonora, 14 posições do sonómetro e 2 leituras em cada local de medição).

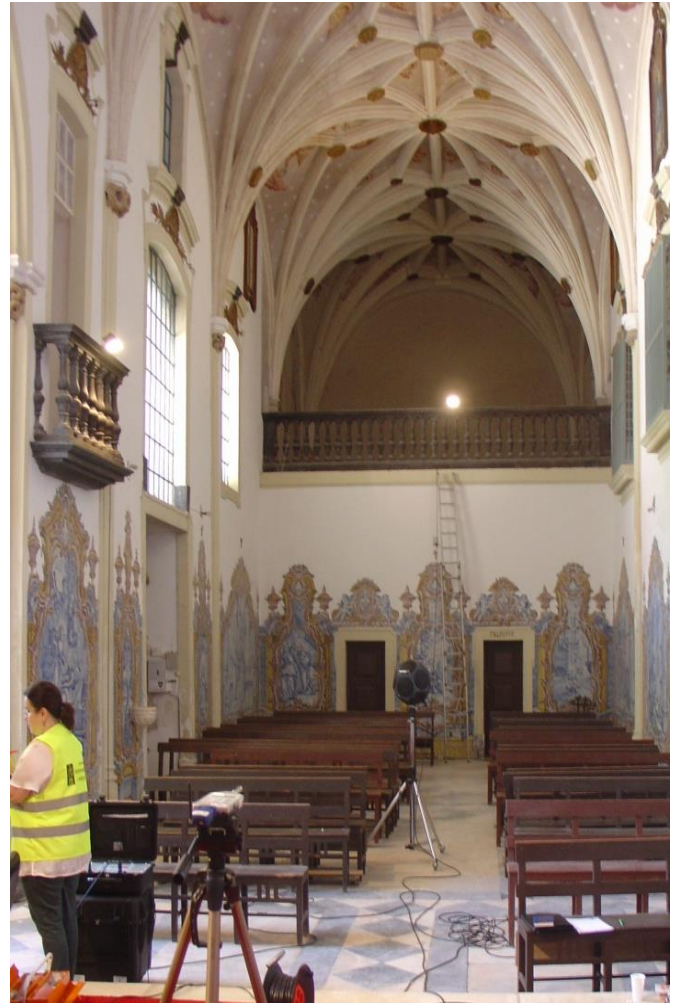

Fig. 22 - Medição com fonte sonora na posição F05 e recetor na posição $\mathrm{R} 02$

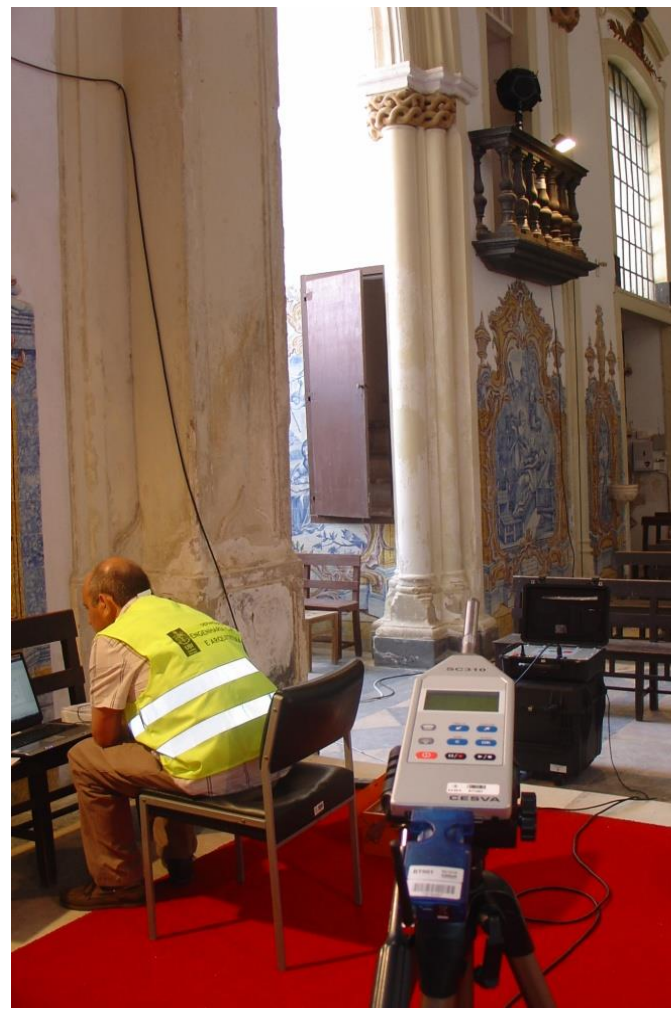

Fig. 23 - Exemplo de medições com fonte sonora colocada na posição F04 e recetor na posição R01

A metodologia de medição consistiu nas seguintes etapas principais: 1) calibração do equipamento em função das condições de temperatura e humidade relativa do local; 2) estabilização do nível de ruído de fundo; 3) emissão sonora; 4) extinção do som emitido (exigindo silêncio absoluto aos operadores para evitar interferência nas medições); 5) registo do decaimento e 6) repetição do processo, efetuando outra medição ou deslocando recetor. 
O trabalho efetuado devido à sua complexidade, apresentou algumas dificuldades, que devem ser ponderadas em estudos posteriores no caso de se pretender fazer um trabalho de medição igualmente circunstanciado. Enumeram-se de seguida algumas das dificuldades principais:

- Escassez de tempo para preparação do trabalho;

- Inexistência de acesso direto ao coro alto;

- Número significativo de medições efetuadas e tempo necessário para o efeito;

- Necessidade de silêncio absoluto durante os procedimentos de medição do $T r$, o que exige operadores bem treinados e acesso restrito aos recintos a estudar.

\section{Resultados esperados e trabalhos futuros}

O estudo efetuado de forma alguma se considera completo e terá de ser continuado em fase posterior com o objetivo de validar a estratégia e metodologia de medição.

As medições efetuadas serão agora objeto de tratamento de dados com produção de relatórios circunstanciados. Serão analisados os tempos de reverberação medidos e a sua distribuição em função dos diferentes posicionamentos das fontes sonoras. Estes resultados permitirão tentar justificar a alternância de utilização do coro alto e do coro baixo em épocas diferentes e fornecer dados para a melhor localização de atividades musicais diferentes.

Serão também analisadas as possibilidades de tratamento acústico do espaço e a sua adaptabilidade para outras funções.

\section{Conclusões}

A realização deste trabalho confirmou o interesse e atualidade do estudo da acústica interior nos espaços destinados a atividades litúrgicas, em especial nos espaços utilizados pela Ordem de Cister ao longo dos tempos. Os níveis de conforto acústico devem ser garantidos em todos os espaços utilizáveis de forma a otimizar-se a transmissão dos sons e as condições de audição que são essenciais para todos os membros da audiência e os estudos deste tipo devem ser continuados. 
Agradecimentos e notas

Esta comunicação resulta de trabalho desenvolvido para o Projeto FCT EXPL/EPH-PAT/2253/2013, Projeto ORFEUS - A Reforma tridentina e a música no silêncio claustral: o mosteiro de S. Bento de Cástris, projeto financiado FCT com co-financiamento comunitário, através do COMPETE - Programa Operacional Factores de Competitividade, do QREN e da União Europeia (FEDER) sendo a instituição proponente a Universidade de Évora, através do Centro Interdisciplinar de História, Culturas e Sociedades (CIDEHUS), e sendo a Universidade da Beira Interior uma das instituições parceiras conjuntamente com a Universidade do Minho e a Universidade dos Açores.

Este trabalho apenas foi possível concretizar-se com a cedência de equipamentos do Laboratório de Saúde na Edificação (LABSED) do UBIMedical da Universidade da Beira Interior.

\section{Referências}

[1] CONDE, A., A afirmação do Mosteiro de São Bento de Cástris no contexto local e nacional in "Actas do Colóquio Internacional - Cister: Espaços, Territórios, Paisagens / Mosteiro de Alcobaça, Junho 1998”, vol. I, Ministério da Cultura, Instituto Português do Património Arquitetónico, Lisboa, 2000.

[2] MARTINS, A. M., As Arquitecturas de Cister em Portugal. A actualidade das suas reabilitações e a sua inserção no território, Tese doutoramento, Universidade de Sevilha, Espanha, 2011.

[3] REIS C., Mosteiro de São Bento de Cástris - Música vs. Arquitectura, Diss. em Arquitetura, Or.: Ana Martins e M. Antónia Conde, UBI, Covilhã, Portugal, 2014.

[4] RRAE, Regulamento dos Requisitos Acústicos dos Edifícios, Decreto-lei n. ${ }^{\circ}$ 96/2008 de 9 de junho, Ministério do ambiente, do ordenamento do território e do desenvolvimento regional, Diário da República, 1. ${ }^{a}$ série - n. ${ }^{\circ} 110$ - 9 de junho de 2008, pág. 3359 e seguintes, Lisboa, Portugal, 2008.

[5] EN ISO 3382-2 - Acoustics - Measurement of room acoustic parameters Part 2: Reverberation time in ordinary rooms, 2008. 
[6] RIGDEN, J.S., "Physics and the sound of music", Wiley, New York, USA, 1985. 